\section{Os métodos quantitativos, por cientistas sociais brasileiros: entrevistas com Nelson do Valle Silva e Jerônimo Muniz}

Recebido: 03.01.17

Aprovado: 29.08 .17

\author{
Natasha Bachini \\ \& Tathiana Senne Chicarino*
}

Resumo: Nos últimos anos, tem-se observado crescente interesse no estudo e na utilização de técnicas quantitativas nas ciências sociais. Do mesmo modo, verifica-se a ampliação do debate acerca de seus usos e a criação de novas ferramentas e abordagens para a aplicação da metodologia quantitativa em estudos sociais e políticos. Com o objetivo de refletir sobre essas questões a partir da experiência teórica e empírica, realizamos entrevistas com dois professores/pesquisadores de diferentes gerações, que são referências importantes na área, o Prof. Dr. Nelson do Valle Silva, do Instituto de Estudos Sociais e Políticos da Universidade do Estado do Rio de Janeiro (IESP-UERJ) e o Prof. Dr. Jerônimo Muniz, da Universidade Federal de Minas Gerais (UFMG).

Palavras-chave: metodologia quantitativa, biografia, ciências sociais, estatística, ensino e pesquisa.

\section{Introdução}

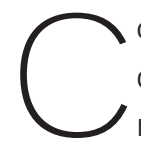

om o objetivo de contribuir para a discussão acerca do emprego de métodos quantitativos nas ciências sociais brasileiras, sua importância e suas singularidades, entrevistamos dois professores/pesquisadores importantes da área, que representam gerações distintas desse processo, de modo a privilegiar sua dimensão histórica e compreender seu estado atual: o Prof. Dr. Nelson do Valle Silva, do Instituto de Estudos Sociais e Políticos da Universidade do Estado do Rio de Janeiro (IESP-UERJ) e o Prof. Dr. Jerônimo Muniz, da Universidade Federal de Minas Gerais (UFMG).

As entrevistas, realizadas em 2015¹, foram orientadas por um questionário semiestruturado e organizado em quatro blocos. No primeiro procuramos enfatizar a trajetória pessoal dos entrevistados a partir da frutífera articulação da biografia com a história - sendo essa entendida como a conjuntura observada e vivida - para, a partir de então, poder vincular as experiências pessoais aos processos sociais mais amplos, naquilo que Mills (1975) chamou de momentos heurísticos orientados para a problematização e o entendimento da realidade. O segundo e o terceiro blocos estão organicamente estruturados, para primeiro pôr luz à especificidade da me-

\footnotetext{
* Natasha Bachini é doutoranda no Programa de Pós-graduação em Sociologia do lespUerj, Rio de Janeiro (RJ), Brasil, e mestre em ciências sociais pela PUC-SP. Atua como pesquisadora no Núcleo de Estudos de Teoria Social e América Latina (Netsal), no Núcleo de Estudos em Arte, Mídia e Política (Neamp) e no Laboratório de Estudos de Mídia e Esfera Pública (Lemep), onde coordena o projeto M Facebook. <natashabachini@ iesp.uerj.br>.

Tathiana Senne Chicarino é doutoranda no Programa de Estudos Pós-graduados em Ciências Sociais da PUC-SP, São Paulo (SP), Brasil, e mestre pela mesma instituição. Atua como pesquisadora no Núcleo de Estudos em Arte, Mídia e Política (Neamp), no Grupo de Pesquisa "Comunicação e Sociedade do Espetáculo", da Casper Líbero, e como professora na Fundação Escola
} 
de Sociologia e Política (Fesp-SP). <tschicarino@gmail. com>.

\section{Nossa proposta} inicial era realizá-las presencialmente com os dois professores, porém, devido a um conflito de agendas, só conseguimos proceder dessa maneira com o Prof. Nelson do Valle Silva. O Prof. Jerônimo Muniz nos respondeu por e-mail.

2. A esse respeito, Soares (2005) chama a atenção para a relevância do antigo luperj (atual lespUerj) na formação quantitativa dos cientistas sociais brasileiros ao longo dos últimos 50 anos, onde Nelson do Valle Silva é professor desde a data referida. Além disso, Figueiredo Filho et alii (2011), Gláucio Soares (2005), Neiva (2015) comentam sobre o importante papel do curso de inverno de metodologia quantitativa (MQ), oferecido pelos departamentos de Sociologia e Ciência Política da UFMG, curso do qual o professor Nelson do Valle Silva foi um dos fundadores (1999) e que conta com o professor Jerônimo Muniz como seu atual coordenador. todologia quantitativa no brasil, tanto no que se refere ao conteúdo, quanto à sua prática, ou seja, da teoria à empiria; e depois estendendo a sua compreensão para as ciências sociais em geral.

No que se refere ao estado da arte da metodologia quantitativa no Brasil, cabe destacar o entrincheiramento (Cano, 2012) observado nesse campo, entre aqueles que a priori recusam qualquer processamento quantitativo de informações e os que enquadram como não científica toda e qualquer pesquisa não quantitativa (Soares, 2005), e a existência de gradações entre as disciplinas, sendo que a ciência política é mais aberta do que a sociologia, e a antropologia menos do que as duas (Soares, 2005; Reis, 1993). Neiva (2015) confirma tais posições ao avaliar o uso de dados e métodos quantitativos em 22 revistas científicas na área das ciências sociais, chegando aos seguintes resultados:

De fato, a ciência política apresentou-se bem mais "quantitativa" do que as outras disciplinas ( $43,8 \%$ dos artigos). Contrasta fortemente com o que aconteceu com a sociologia $(20,7 \%)$, na história $(15,7 \%)$ e na antropologia $(13,2 \%)$. No que se refere à estatística avançada, os cientistas políticos a usaram em $14 \%$ dos artigos. Uma proporção pequena, mas bem acima de todas as outras (Neiva, 2015: 75).

Assim, a despeito de ter aumentado nos últimos anos, o número de cientistas sociais que se dedica à metodologia quantitativa é pequeno, tornando-se injustificável quaisquer "guerras metodológicas" (Neiva, 2015: 80).

Uma hipótese explicativa para tal fato, segundo Figueiredo Filho et alii (2011: 46), é a falta de domínio das técnicas de estatística descritiva e inferencial por grande parte dos pesquisadores, o que resulta em sua baixa aplicação nos trabalhos acadêmicos $^{2}$. Nesse sentido, Soares (2005) sugere que o desenvolvimento tecnológico, no que diz respeito ao processamento e armazenamento de crescentes e diversificadas fontes, dados e informações, por um lado, faz com que a necessidade de formação e treinamento sofisticados seja cada vez mais premente e, por outro, nos abriu novas perspectivas para o fim da barreira entre as metodologias qualitativas e quantitativas. Desse modo, a distinção entre método qualitativo e quantitativo é menos uma antinomia metodológica, teórica ou epistemológica e mais uma "[...] dinâmica lógica e progressiva do esforço investigativo, a qual envolve dois recortes em última instância indissolúveis" (Ramos, 2013: 56).

Nestas entrevistas os professores ressaltam que, para além da opção por técnicas quantitativas durante a feitura de uma pesquisa social, devemos nos atentar para 
a rigorosa utilização de uma metodologia de análise, e nesse âmbito, a abordagem quantitativa dispõe da vantagem de apresentar

procedimentos que atingem maior grau de padronização e podem ser prontamente comunicados (tipo e tamanho da amostra, erro amostral etc.), de forma que possam ser replicados ou contestados com maior facilidade (Cano, 2012: 109). ${ }^{3}$

Tal característica é fundamental, visto que a possibilidade de replicação de nossa pesquisa por outros pesquisadores é um requisito na obtenção da fidedignidade, a base da objetividade científica (Ramos, 2013: 58).

Finalmente, o último bloco tratará da relação entre a metodologia quantitativa e a metodologia qualitativa e, sobretudo, da importância do método, sistematicamente empregado, no estudo da realidade social. Com isso, buscamos através da pertinente vocalização de nossos entrevistados contribuir para arrefecer a hostilidade dos cientistas sociais em relação aos métodos estatísticos (Soares, 2005) e para a problematização da produção do conhecimento científico, no que se refere à utilização de técnicas qualitativas e/ou quantitativas a depender do problema de pesquisa (Ramos, 2013), já que cada qual possui vantagens e desvantagens no que tange à obtenção dos dados, sua utilização e análise (Gunther, 2006: 201). Assim, a formulação da hipótese - ainda que não definitiva (um aspecto epistemológico) - do problema de pesquisa que se quer compreender é que vai orientar nossa escolha teórica e metodológica, já que "cada método e técnica de pesquisa fornece uma perspectiva diferente do mundo" (Ramos, 2013: 58).

\section{Trajetórias}

De início, gostaríamos que você nos contasse sobre a sua trajetória profissional e formação acadêmica relacionada à metodologia quantitativa. Como iniciou na área de métodos quantitativos? Qual é a sua atual vinculação institucional, linha de pesquisa e projetos em andamento?

Nelson do Valle Silva: Vamos tentar organizar, porque retomar 70 anos não é fácil, mas vamos lá. Eu iniciei a minha graduação na PUC, na Escola de Sociologia e Política, em 1965. Só que eu fiz economia, porque, naquela época, o departamento de economia, era dentro da sociologia.

Com a reforma da universidade, em 1966, foi criado um departamento próprio para a economia e eu migrei para lá. [...] A partir do segundo ano, eu fui descobrindo que
3. Cano (2012:

107) faz a distinção entre métodos que seriam as estratégias de produção de conhecimento científico, incluindo a geração e a validação de teorias, portanto, mais abrangente, e técnicas que seriam as formas padronizadas de coleta e análise de dados, com a mesma finalidade, a de produzir conhecimento válido, mas que são mais específicas e concretas. 
não gostava nem um pouco de economia, não a entendia muito bem. Entretanto, [...] eu pretendia me casar e precisava trabalhar. Foi quando decidi cursar a cadeira de programação de computadores na economia. Para você ter uma ideia, o computador ainda era a válvula.

No meu último ano de faculdade, recebi o convite do Departamento de Matemática da PUC-RIO, que estava organizando sua área de Informática junto com a IBM para fundar o Rio Data Centro. [...] Após a fundação do Rio Data Centro, foi criado o Departamento de Informática da PUC-Rio (1970), e a partir de então, eu passei a trabalhar lá como professor-assistente de computação para ciências sociais [...].

Com a reforma universitária, eu tive que fazer mestrado em informática para continuar lecionando no departamento da PUC-Rio. Mesmo odiando tudo aquilo, eu o fiz porque tinha que ganhar dinheiro para viver. E naquela época, informática dava uma nota absurda!

Nesse mesmo período, o IBGE estava se reformando, tinha um novo presidente, que era o professor Isaac Kerstenetzky, que estava tentando reerguer a instituição depois do fiasco do Censo de 1960, que não tinha sido processado, e ainda tinha de ser realizado o novo Censo de 1970.

Trabalhando no Rio Data Centro eu conheci muita gente das ciências sociais. O pessoal do Instituto Universitário de Pesquisas do Rio de Janeiro (Iuperj) era um dos usuários do Rio Data Centro. Além disso, uma das minhas colegas no departamento de Informática era a Profa. Sueli Bandeira Teixeira Mendes, então esposa do Prof. Wanderley Guilherme dos Santos.

Na informática, meu papel era apoiar e ajudar as pessoas das ciências sociais. Por exemplo, a Profa. Neuma Aguiar tinha que fazer análise de variância para a sua tese de doutorado, então eu fiz um programa de análise de variância para ela. Desse modo, eu fui conhecendo muitas pessoas da área, inclusive o pessoal da geografia do Instituto Brasileiro de Geografia e Estatística (IBGE).

Assim, pela primeira vez, em 1971, eu dei um curso de análise de dados no luperj, a pedido do Wanderley. Nesse mesmo ano, com a reformulação do IBGE, o pessoal da geografia me convidou para trabalhar lá. Nesse sentido, a primeira escolha que eu fiz academicamente, foi na área da geografia. A gente trabalhava com regionalização, sistema de cidades etc. O primeiro artigo que eu escrevi na minha vida foi sobre um algoritmo para identificação de polos de crescimento. 
Só que, pouco depois de eu ir para o IBGE, comecei a trabalhar com demografia e estratificação social, especialmente porque eu tinha à disposição os dados do Censo, e me interessava pela questão da desigualdade. A partir de então, eu fiquei com meus pés em lugares distintos: um no IBGE e o outro no luperj. E assim fiquei a vida toda.

O primeiro curso que eu dei no luperj foi a quatro mãos, com o Prof. Simon Schartzman. Nós dávamos o curso de metodologia estatística. A gente usava o computador da PUC, do Rio Data Centro. Os alunos iam lá, coitados, com aqueles cartões holerite, e rodavam os programas.

Já tinha o Statistical Package for the Social Sciences (SPSS), mas eu desenvolvi minha tese de mestrado em um sistema muito parecido com o SPSS, chamado Interpretador de Comando Estatístico (ICE). O ICE tinha acabado de ser lançado. Era também um software mais voltado para as ciências sociais.

Ao mesmo tempo, lá no IBGE eu estava no Departamento de Informática e junto com o grupo da geografia, da física e da matemática, nós tentamos montar uma equipe interdisciplinar para estudar questões socioeconômicas. No bojo disso, existia um programa de capacitação, de aperfeiçoamento para o serviço público patrocinado pelo convênio MEC/Usaid, com o governo americano.

Naquela época, todos os meus amigos, como Amaury de Souza, Peter McDonough, que eram daqui do luperj, estavam em Michigan, nos Estados Unidos. Em Michigan, a sociologia era especializada em demografia e estratificação social. É importante ressaltar que a demografia tinha como foco nesse momento população e ecologia humana.

Essas condições me levaram a Michigan em 1974 para fazer meu doutorado em sociologia. [...] A área de concentração do meu título foi população e ecologia humana, mas a minha tese foi em estratificação, a área de concentração menor.

Quando eu voltei para o Brasil, me puseram como chefe de departamento de estudos da população, onde trabalhei por dois anos. Eu fui colocado ali estrategicamente, para tentar acalmar os ânimos, pois tinha morrido o chefe desse departamento, o Prof. Iran Madeira. Então me chamaram porque eu jogava nas duas áreas, na sociologia e na demografia. E eu tentei fazer isso durante esse tempo, mas o clima estava muito ruim. Derrubaram até o presidente do IBGE, o Prof. Isaac Kerstenetzky. 
Em 1979, assumiu o seu lugar o Prof. Jessé de Souza Montello, com o discurso de que o IBGE não era lugar de fazer pesquisa; a função do IBGE era coletar dados e por isso não tinha que ter departamento de pesquisa. Aí a situação piorou. Passamos dois anos brigando, até que eu um dia, não aguentei mais e saí do instituto.

No entanto, um pouco antes da minha saída, o grupo da informática do IBGE tinha migrado em massa para o Centro Brasileiro de Pesquisas Físicas, no CNPq, e lá fundou o Laboratório Nacional de Computação Cientifica (LNCC), [...] que me convidaram a integrar em 1980.

$[\ldots]$

De 1980 em diante trabalhei nesses dois lugares, o LNCC e o luperj até que me aposentei, em 2000, no LNCC, porque esse mudou para Petrópolis. [...] Depois disso, fiquei só no luperj, agora lesp, e continuei com a mesma linha de pesquisa, que é estratificação social e mobilidade, e dando as aulas de metodologia estatística.

Além disso, uma coisa que eu não falei, é que eu fui um dos fundadores do Programa de Treinamento Intensivo em Metodologia Quantitativa da Universidade Federal de Minas Gerais (MQ- FMG), em 1999, e lá dei o curso básico durante quase dez anos.

O MQ foi criado pela Profa. Neuma Aguiar, que era presidente de Sociedade Brasileira de Sociologia (SBS). O presidente anterior, o Prof. Antonio Sergio Guimarães, da Universidade de São Paulo (USP), tinha me encomendado um projeto de um curso de métodos quantitativos semelhante ao que tinha em Michigan, e quando a Neuma assumiu a SBS, decidiu levar a ideia adiante.

No âmbito das pesquisas, dentre outras, fui o diretor de um projeto do Instituto do Milênio, chamado "A dimensão social das desigualdades: sistemas de indicadores de estratificação e mobilidade social", desenvolvido aqui no luperj. Esse projeto consistiu em um survey nacional sobre desigualdade.

Os métodos quantitativos, ao contrário do que muita gente acha, que só servem para constatar o que você já sabe, devem ser usados para descobrir o que você não vê. Para diagnosticar aquela realidade que está ali e você não vê porque ela está ali sob dimensões latentes.

Nesse sentido, fiz muitas descobertas importantes. Um exemplo delas se refere a área da mobilidade, a estrutura da mobilidade no Brasil. Eu poderia resumir, como 
fiz uma vez, que essa é uma estrutura extremamente fechada, inundada pela mobilidade estrutural, ou seja, você tem uma mudança na estrutura que inunda uma estrutura de classes muito rígida. Isso você não vê. Você tem que olhar os dados para descobrir.

A minha tese de doutorado é sobre desigualdades raciais. Nela, tentei mensurar a discriminação no Brasil. Tentei mostrar que a discriminação existe, que não é redutível à classe, à determinação de classe, que existe uma dimensão independente, especificamente racial, na questão da estratificação, e que isso também você não vê. Você tem que rodar os números para poder demonstrar.

Jerônimo Muniz: Onde se inicia a trajetória profissional de alguém? O que condiciona as escolhas que fazemos? [...] Os caminhos que seguimos resultam de preferências e oportunidades. Nossas preferências são moldadas por processos de socialização. Eu decidi me tornar economista. Na época do vestibular, era o curso que melhor combinava meus interesses por matemática, geografia, português e história. Fiz vestibular na UFMG e na USP, mas como as datas da segunda etapa do processo seletivo da Fuvest coincidiam com as da UFMG, escolhi, por conveniência, ficar em Minas. Em 1996 entrei na Faculdade de Ciências Econômicas (Face), onde fiz quatro cursos de matemática, dois de estatística e dois de econometria, além de três de micro e macroeconomia. Na época, não entendi o propósito de cálculos diferenciais, matrizes transpostas, inversas, pontos de maximização, funções hiperbólicas, mínimos quadrados ordinários e nem a utilidade de se provar que dois era par. Não via finalidade em nada disso. Todo aquele conteúdo ficou latente por um bom tempo; só fui perceber sua utilidade no mestrado e no doutorado. Só mais tarde me dei conta de que eles haviam condicionado minha mente, minha lógica.

Durante a graduação, fui bolsista de Iniciação Científica do Prof. Eduardo Rios-Neto, do Departamento de Demografia. Sob sua supervisão, [...], estudei padrões de emulação de consumo. A ideia era investigar se as famílias consumiam bens compatíveis com suas rendas ou se havia alguma preferência por bens de consumo que sinalizassem status e prestígio de outras classes sociais. Foi um estudo baseado na teoria da classe ociosa de Veblen (1899). Eduardo também orientou minha monografia, na qual investigamos, a partir da Pesquisa Nacional por Amostra de Domicílios (Pnad), a decisão simultânea das crianças entre trabalhar e estudar usando um modelo probit bivariado, algo avançado para um trabalho final de graduação. A inspiração deste trabalho, entretanto, foi responsabilidade de Daniel Miles, professor de econometria da Universidad de Vigo, na Espanha, onde passei três meses do meu último ano de bacharelado. Estes trabalhos foram premiados 
e apresentados em congressos nacionais e internacionais, embora nunca tenham sido publicados.

Enquanto terminava a graduação, fiz estágio na Usiminas e tentei ingressar em diversos programas de trainee, mas não fui selecionado. Até então, não vislumbrava uma carreira acadêmica; eu mal sabia a diferença de um mestrado para um doutorado. Resolvi, para diminuir o risco do desemprego, inscrever-me no processo de seleção do mestrado em demografia do Centro de Desenvolvimento e Planejamento Regional (Cedeplar/UFMG). [...]

Em 2000, aprovado no mestrado em demografia, fui novamente exposto, agora com maior maturidade, a cursos de matemática e estatística, e também à modelagem hierárquica e à análise de sobrevivência. Isso resultou em uma dissertação recheada de modelagens econométricas (ex. decomposição de Oaxaca e modelos lineares generalizáveis factíveis), que utilizei para investigar o diferencial de rendimento entre pessoas casadas e solteiras (marriage premium) no Brasil, e para estudar se o tamanho de coortes de nascimento específicas teria algum efeito sobre taxas de ocupação e desemprego das regiões metropolitanas brasileiras. Este último capítulo da dissertação tornou-se minha primeira publicação formal, na Revista Brasileira de Estudos de População (Muniz, 2002).

Quando estava terminando o mestrado, me deparei novamente com o dilema que havia me afligido no final da graduação - tentar uma inserção no mercado ou continuar a carreira acadêmica? Não via perspectiva mercadológica imediata para demógrafos, e vários ex-alunos próximos à minha coorte [...] também haviam feito mestrado na demografia do Cedeplar e, em seguida, partido para o exterior fazer doutorado nas melhores universidades do mundo. O Eduardo, meu orientador, me assegurou que estudar nos Estados Unidos seria uma opção mais promissora do que continuar os estudos no Brasil. Ele estava certo.

Tentei entrar em Berkeley, Stanford, Michigan, Yale, Harvard e Wisconsin. Estas ainda abrigam os melhores departamentos de sociologia do mundo, e esse foi o critério que utilizei para decidir aonde iria. Só fui aceito na Universidade de Wisconsin (UW), em Madison, onde vivi por cinco anos. [...]

Meu mestrado do Brasil não foi validado pelo Departamento de Sociologia de Madison, mas minha formação em economia e demografia me permitiu dispensar três semestres obrigatórios de cursos de estatística. Fui direto para um curso avançado de dados categóricos, lecionado pelo Prof. John Logan. Durante o doutorado, cursei novamente análise de sobrevivência, mas também me matriculei em cur- 
sos sobre sistemas dinâmicos complexos, métodos de demografia formal e epidemiologia. Esse foi o meu treinamento curricular em metodologia quantitativa. Fiz cursos de curta duração na Universidade de Stanford, novamente em demografia formal, e também participei de um workshop interdisciplinar na Pennsylvania State University, organizado pelo Prof. Stephen Mathews, sobre georreferenciamento e análise espacial de dados. Gostei tanto do assunto que escrevi minha segunda dissertação sobre isso, sob a supervisão do Prof. James Raymo, que não entendia muito do campo, mas fez um trabalho de orientação exemplar (Muniz, 2009). Mais tarde, em 2006, dei um curso de 15 horas sobre análise espacial no programa de treinamento intensivo em metodologia quantitativa (MQ) da UFMG, sob convite da Profa. Neuma Aguiar, fundadora do programa que hoje coordeno.

O Departamento de Sociologia da UW é um milieu privilegiado para se fazer pesquisa. [...] Havia uma troca acadêmica enorme entre colegas, [...] por meio dos chamados brown bags. Quase todas as linhas de pesquisa do departamento (psicologia social, economia política, sociologia da raça, demografia, sociologia rural, sociologia da educação etc.) organizavam seminários semanais ou quinzenais nos quais professores e alunos apresentavam suas pesquisas para submetê-las à revisão de pares e testar a relevância dos assuntos pesquisados. Os brown bags nos ajudavam a treinar a oratória, a desenvolver a autoconfiança e a validar a relevância de ideias. Sinto falta disso no Brasil. [...]

Também foi muito importante para a minha formação, e diria crucial para minha inserção e trajetória profissional, ter trabalhado com a Profa. Mara Loveman, hoje em Berkeley. Com ela aprendi a ser exigente e a buscar clareza na escrita. [...] Nosso primeiro contato foi motivado por um trabalho encomendado pela United States Library of Congress. A empreitada consistia em ler, filtrar e sistematizar o que havia sido produzido de mais relevante na sociologia brasileira nos últimos cinco anos. Assim, passamos meses entre pilhas e caixas de material bibliográfico a fim de produzir um capítulo de cinco páginas sobre a sociologia brasileira, que acabou sendo publicado no Handbook of Latin American Studies (Loveman, Muniz \& Collares 2008). Esse foi meu primeiro trabalho de cunho estritamente sociológico.

Enquanto trabalhávamos no capítulo do Handbook perquirimos por que a população branca de Porto Rico havia aumentado tanto entre 1910 e 1920. Esta investigação, que culminou em uma publicação na American Sociological Review (Loveman \& Muniz 2007), foi o início de outras colaborações que faríamos com o Prof. Stanley Bailey, da UC-Irvine, a fim de investigar processos de reclassificação racial e o impacto dos mesmos sobre medidas de desigualdade (Bailey, Loveman \& Muniz 2013; Loveman, Muniz \& Bailey 2012). Esta acabou se tornando a minha 
linha de pesquisa na sociologia, embora pouco tenha tido a ver com a minha tese de doutorado.

Na tese, investiguei a dinâmica demográfica da pobreza e da desigualdade de renda no Brasil entre 1980 e 2000. Projetei qual seria o crescimento das classes sociais (pobres, classe média e ricos) ao longo do tempo caso não houvesse processos de mobilidade envolvidos. A principal contribuição do trabalho foi mostrar como métodos de projeção e simulação podem separar a demografia da mobilidade social na dinâmica de crescimento das classes de renda (Muniz, 2012a).

Defendi a tese em 2008. Em 2009, voltei ao Brasil para fazer pós-doutorado no Núcleo de Estudos de População (Nepo), na Unicamp, e, no mesmo ano, tornei-me pesquisador concursado da referida instituição; iniciei minha carreira como demógrafo, e não como sociólogo.

No ano seguinte, fui para a UFMG por estar com saudades de Belo Horizonte e por considerar a carreira docente mais promissora. Com tal transição profissional, passei a fazer contribuições esporádicas para a demografia.

Minha carreira voltou-se então a assuntos sociológicos, embora a interface com a economia e com a demografia continuasse através da constante utilização de bases de dados e da abordagem quantitativa para testar e pautar teorias na empiria. As minhas pesquisas sobre religião, classificação e desigualdade raciais evidenciam isso (Muniz, 2010, 2012b; Silveira \& Muniz, 2014; Rosas \& Muniz, 2014).

Os cursos que já ofereci e ofereço na UFMG também corroboram o meu perfil quantitativo. Desde que ingressei na Faculdade de Filosofia e Ciências Humanas (Fafich) tenho lecionado sobre métodos estatísticos no bacharelado e no Programa de Pós-Graduação em Sociologia. Além destes, também leciono introdução à sociologia, sociologia da raça/cor e seminários avançados de estratificação e desigualdade, tema este que define uma das linhas à qual estou vinculado. A segunda linha da qual faço parte é a de sociologia das populações, por conta do meu interesse pela demografia.

As pesquisas que conduzo hoje refletem o hibridismo da minha formação e meus interesses precedentes. Minha grande meta científica consiste em acompanhar e mensurar os diversos tipos de incerteza envolvidos no processo de classificação racial, assim como o impacto da mesma sobre a percepção e a construção das desigualdades. Em minhas publicações, tenho discorrido sobre as incertezas taxonômicas, espaciais, temporais, amostrais, cognitivas e contextuais envolvidas no 
processo de (re) classificação racial, mas ainda há muita coisa a ser feita e perguntas para se responder.

Outros temas de pesquisa, como o desenvolvimento de métodos para previsões populacionais de pequenas áreas, desigualdade de gênero, religião e redes sociais também fazem parte da minha agenda de investigação científica.

De modo complementar, atuo na direção do Centro de Pesquisas Quantitativas em Ciências Sociais (Cpeqs) e na coordenação do MQ, que herdei do Prof. Antônio Augusto no final de 2013. Ambas as funções contribuem para que eu esteja a par do desenvolvimento de novos métodos e de treinamentos relevantes para as Ciências Sociais.

\section{Sobre o ensino de}

\section{metodologia quantitativa no Brasil}

Gostaríamos de saber, a partir de sua experiência quais diferenças podem ser destacadas no ensino de Metodologia Quantitativa ao longo dos anos, especialmente em relação a:
i. conteúdo;
ii. tecnologia disponível; e
iii. perfil e interesse dos alunos.

Nelson do Valle Silva: Primeiro você tem como pano de fundo o desenvolvimento muito grande da parte de Informática. O desenvolvimento maior não é em termo da tecnologia de análise, nas técnicas de análise, é mais na acessibilidade. O microcomputador permitiu a todo mundo fazer análise de dados e esse é um grande diferencial.

Em termos de tecnologia, basicamente essas coisas já existiam. O que a gente usa é quase tão velho quanto andar para frente. Aliás, essas técnicas, a regressão, existem desde o início do século XX. Isso é algo já muito consolidado. O que mudou realmente foi a acessibilidade, que permitiu você avançar mais rapidamente nos conteúdos. Sem ter que precisar fazer tudo à mão, se tornou fácil fazer. E, sobretudo, a questão gráfica, a computação gráfica permitiu a identificação de padrões. A análise de dados é a identificação de padrão (pattern recognition). Você olha e identifica um padrão. Você lê aquele padrão assim como um médico lê uma radiografia. 
A computação também teve avanços imensos nessa parte gráfica, que permitiu o desenvolvimento da análise visual, do reconhecimento de padrões. Acho que isso foi fundamental.

O interesse por metodologia quantitativa sempre foi modesto, para dizer assim, diretamente, discretamente. Sempre foi muito modesto, mas está crescendo. Eu acho que uma das razões importantes desse crescimento está na popularização das pesquisas, em especial, das pesquisas eleitorais, que mostraram a importância e a validade do método. Hoje todo mundo quer saber qual é a popularidade da Dilma (Roussef); sabe o que é margem de erro. São coisas que as pessoas aprenderam, que se popularizaram.

Uma coisa que era muito questionada era a validade do método, para que serve isso. Alguns diziam: "isso que está sendo produzido não vale nada", "é tudo uma invenção". No entanto, o que as pesquisas eleitorais mostraram, mostram é que sim, funciona. Você prevê o resultado. É válido porque permite a previsão.

Isso se reflete no aumento da aplicação da estatística nas monografias e teses, sobretudo, nessa área de estratificação política, da questão do voto. A pesquisa eleitoral é uma área importante dentro da política, e sem a análise quantitativa, ela não existe.

Além disso, surpreendentemente, existe um mercado de trabalho muito grande para quem sabe aplicar esses métodos. Mas, infelizmente, os alunos de graduação só se dão conta disso depois de terem se recusado a aprender. Aí é que eles se dão conta que o que existe de mercado de trabalho são os institutos de pesquisa, as universidades e as pesquisas. Além de dar aula, é isso que tem de mercado. [...]

Jerônimo Muniz: As minhas impressões referem-se aos últimos quinze anos. As mudanças que a internet, o e-mail, o Twitter e sobretudo o Google geraram sobre as formas de interação, comunicação e aprendizado são evidentes. Estamos on-line e a informação propaga-se a uma velocidade nunca antes experimentada. Assimila-se conteúdo de forma rápida e em diferentes níveis de profundidade. Há informações gerais e específicas sobre praticamente qualquer assunto. Há uma disponibilidade enorme de dados estatísticos, de material bibliográfico, de vídeos, blogs, e fóruns de discussão. Programas para análise e visualização de Big Data tornaram-se muito mais acessíveis do que no passado. Ter domínio sobre esses programas é um diferencial desta era. Pesquisas em bibliotecas físicas estão caindo em desuso, e o que não se encontra via Google, e em formato eletrônico e gratuito, está se tornando obsoleto, já que não pode ser facilmente encontrado. Bibliografias e materiais di- 
dáticos são disponibilizados on-line através de plataformas educacionais como o Moodle, enciclopédias livres (Wikipédia) e palestras (TED talks). Vídeo-aulas com professores das melhores universidades do mundo podem ser acompanhadas através de iniciativas exemplares como Coursera, edX e Khan Academy. A tecnologia da informação voltou-se para a resolução de questões e não para a formação de conhecimento de base. Hoje não se aprende para depois se resolver um problema. Tem-se um problema e depois se busca uma solução. O Exame Nacional do Ensino Médio (Enem) tem esse formato, e as novas didáticas sugerem que cursos presenciais - cuja estrutura de funcionamento é herdada da Prússia do século XVIII - também o tenham.

O papel tradicional do professor presencial, tal como estamos acostumados, precisará ser readequado para que seja compatível com as novas tecnologias existentes. O professor não se tornará dispensável, mas o formato atual de suas atividades sim. Ele ainda será fundamental para estruturar e fomentar discussões sobre tópicos do conteúdo, criar atividades práticas, corrigir e elaborar exercícios e sanar dúvidas dos alunos, mas o aprendizado de fato só acontecerá quando o aluno for automotivado e proativo (como sugere Khan, 2013). A questão então é: Como incentivar tal comportamento? Iniciativas baseadas em atividades (activity-based learning models) parecem um caminho pedagógico promissor para promover a participação efetiva dos estudantes em aula, engajando-os no processo de ensino-aprendizagem através da realização de exercícios e discussões de conceitos em sala de aula (Barbería et alii, 2014). Essas metodologias de ensino são uma alternativa ao modelo tradicional de aulas expositivas. Elas têm sido adotadas em cursos de metodologia quantitativa na graduação em ciências sociais na USP, na UFMG e nos cursos de pós-graduação do MQ. O modelo baseado em aulas expositivas de duas a quatro horas é um modelo cansativo. Os que nasceram na década de 1990, a geração universitária atual, tem dificuldade com aulas que requerem longos períodos de foco estático e atenção. Para a geração $Z$, o processo importa menos que o resultado final; entre os nativos digitais há um imediatismo exacerbado que entra em choque com as práticas acadêmico-científicas do passado.

As mudanças ocorridas, ou que ocorrerão no processo de aprendizado, são inerentes à era da tecnologia da informação. Tanto o conteúdo como as práticas didáticas precisam adequar-se à realidade digital e aos novos avanços metodológicos da estatística (vide os debates sobre formas de captação automatizada de dados, e inferência estatística versus bayesiana, por exemplo). Na medida em que a ciência avança, práticas passadas são abandonadas e dão lugar a novas. Quadro negro e giz, retroprojetor e fotocópias perdem espaço para lousas eletrônicas, Power Point, Prezi, documentos digitais e tablets. 
Há indícios de que a incidência de estatística nas monografias, dissertações e teses tem aumentado, mas a prevalência não. Diversas evidências mostram a pequena adesão dos cientistas sociais brasileiros aos métodos quantitativos (Aguiar, 2001; Neiva, 2015; Soares, 2005; Valle Silva, 1999; Viana et alii, 1998). Entre 1957 e 2000, dos 9.118 artigos indexados ao Índice de Ciências Sociais, só 6\% deles eram quantitativos (Aguiar 2001: 3). No final dos anos 1990, menos de 3\% de uma amostra de 308 artigos continham alguma análise quantitativa (Valle Silva, 1999).

Observa-se que ainda há grande resistência ao uso de técnicas estatísticas, tanto por alunos de graduação quanto de mestrado e doutorado. Na USP - instituição que mais forma cientistas sociais no Brasil e que é responsável por 40\% das teses da área defendidas no país - apenas duas das 145 teses defendidas entre 1990 e 1997 tinham caráter quantitativo. No Brasil como um todo, apenas 3\% das 411 teses produzidas durante esse período utilizaram métodos quantitativos (Vianna et al, 1998). [...]Nos últimos 16 anos, a adoção de estatística avançada em trabalhos publicados em periódicos passou de 3,3\% em 1997 para 7,6\% em 2012. Um aumento de 130\%. Especula-se que o $\mathrm{MQ}$ tenha tido alguma responsabilidade sobre esse aumento (Neiva, 2015: 71 e 80; Soares, 2005).

Espera-se que o cientista social seja capaz de escrever bem, mas nem todos são bons em análise de dados. Conhecer metodologias quantitativas é uma vantagem comparativa no mercado de trabalho e será uma habilidade cada vez mais valorizada na era digital. Dados do Censo Demográfico de 2010 trabalhados pelo IPEA (2013) mostram que os egressos dos cursos de sociologia e ciência política ganham em média salários de $\mathrm{R} \$ 3.672,37$. Estes profissionais ocupam a 16a posição no ranking de carreiras universitárias. Já os profissionais formados em estatística ocupam a segunda posição do ranking ( $R \$ 5.416,10)$, atrás somente dos que se formaram em medicina. Além disso, a carreira que mais gerou postos de trabalho no Brasil entre 2009 e 2012 foi a de analista de tecnologia da informação. Ao menos 16 de cada 100 postos de trabalho gerados durante este período foram para profissionais deste setor. Sociólogos com bom treinamento quantitativo, tanto na localização quanto na sistematização e análise de informações publicamente disponíveis, poderiam certamente ocupar postos mais rentáveis (como em institutos de pesquisa, consultorias privadas, e em órgãos de produção e avaliação de políticas públicas), agregando ainda sua capacidade crítica diferenciada.

Na UFMG há atividades extracurriculares consolidadas de treinamento quantitativo tanto na graduação (MQuinho) quanto na pós-graduação (MQ), o que dá aos alunos habilidades práticas específicas para a elaboração de projetos e análises de mercado. O MQ funciona como atividade de extensão e, desde 1999, já recebeu mais 
de 2.500 pessoas de todas as partes do Brasil. Elas vêm para aprender técnicas de metodologia de survey, amostragem, introdução à estatística, regressão linear, grupos focais e, também, cursos intermediários e avançados, como os de R. Stata, Big Data, causalidade, experimentos sociais, dados categóricos, modelos hierárquicos, análise espacial e metodologia qualitativa.

\section{Os métodos quantitativos \\ para as ciências sociais}

Quais aspectos sobre o desenvolvimento da metodologia quantitativa nos estudos sociais e políticos são relevantes do seu ponto de vista?

Nelson do Valle Silva: O que interessa no método quantitativo não é tanto aquela coisa positivista de você ter uma hipótese e rejeitá-la ou não. Trata-se de um convívio com os dados no qual você vai descobrindo o que é que tem ali de baixo com os métodos adequados para isso.

Em outras palavras, sua importância está no processo de descoberta e, portanto, de reelaboração teórica. Você descobre algo que te levará a uma hipótese, que te conduzirá a uma nova reflexão, que te instigará a uma nova coleta. Em suma, é um processo de descoberta que olhando você não vê. Acho que essa é a grande contribuição, o ponto forte dos métodos quantitativos: descobrir coisas novas.

A outra grande contribuição da metodologia quantitativa é a possibilidade de se avaliar a plausibilidade das ideias. O relativismo é muito comum nas ciências sociais. Tudo é igual. A sua opinião de estudante de doutorado e a do professor é igual à do jornaleiro da esquina. Ambas têm o mesmo status epistemológico. As suas ideias são as mesmas.

No entanto, os métodos quantitativos permitem avaliar quais ideias são mais plausíveis. Avaliar relativamente. Isso é mais lógico, mais plausível, empiricamente mais plausível do que a aquela outra ideia. Essa colocação pode ser interpretada como uma relativização do relativismo, mas não é bem assim. Têm coisas que são mais verdadeiras do que outras, que podem ser mais verdadeiras do que outras. Não é tudo igual.

Dos anos 1980 para cá, boa parte da evolução dos métodos estatísticos de análise de dados são provenientes das ciências sociais. Por exemplo, o problema da análise da mobilidade social levou a uma reflexão e a um aprofundamento muito forte dos métodos estatísticos para tratar desse problema. 
Outro exemplo que me ocorre é o da análise das variáveis qualitativas. A grande inspiração para a estatística são as ciências sociais, visto que essas variáveis predominam em suas pesquisas. Então é um caminho de duas mãos, que eu acho muito fértil e acumulativo. O interessante é ser acumulativo, no sentido de ciência mesmo. Por exemplo, a área de estratificação tem um caráter razoavelmente acumulativo. Cada geração tem os seus métodos, que levam a problemas, que são resolvidos tecnicamente, que levam a avanços, que conduzem a novos problemas e assim vai. Obviamente isso não é uniforme para o conjunto das ciências sociais. Há problemas que são mais próximos da análise quantitativa, do tratamento quantitativo, do que outros.

Os métodos quantitativos são fundamentais na formação dos sociólogos das sociedades centrais. Se você faz doutorado nos Estados Unidos ou na Inglaterra, ou mesmo na França (talvez na França um pouco menos, mas mesmo assim), você tem autores como Raymond Boudon que se concentram nessa questão da sociologia como ciência, e para a ciência, o método quantitativo é elementar.

Nos Estados Unidos é impensável (a produção sociológica sem os métodos quantitativos). Dificilmente você encontrará alguma universidade em que os métodos quantitativos não sejam uma coisa muito importante na formação. Na Inglaterra também, é bastante forte. Na França menos, mas ainda assim, é importante. Não podemos nos esquecer que a análise de correspondências é um método francês, que foi propagado pelo mundo inteiro por influência de Pierre Bourdieu e seu livro A distinção (2007).

A análise de correspondências é um método específico, desse como eu estava falando, que nos permite descobrir padrões. Bourdieu observou como o padrão de diversos tipos de capital gera distinção de gosto, estilo de vida etc., usando exatamente o método de análise de correspondência múltipla, criado na França. Ele o usa e o divulgou no mundo inteiro.

Quando eu estudei nos Estados Unidos, ninguém o conhecia. Por acaso, no Grupo da Informática do IBGE, do qual eu participava, tinha um matemático vindo da França, uma grande novidade. A partir de então, nós começamos a trabalhar também com a análise de correspondência. Contudo, somente anos depois, por intermédio de Bourdieu, esse método se espalhou, e agora todo mundo sabe, ou pelo menos já ouviu falar. Aqueles espaços que Bourdieu usa. Todo mundo conhece aquilo, se popularizou.

Veja, esse é um exemplo de coisa não americana, quantitativa, usada pela sociologia mais antiquantitativa que é a sociologia francesa. Além disso, Luc Boltanski e outros 
têm pesquisas nas quais trabalham com survey. Um dia eu ainda escreverei um livro de metodologia só usando o exemplo francês.

Jerônimo Muniz: Entender alguns dos conceitos dos clássicos e como eles se vinculam à prática do cientista social representa o primeiro aspecto relevante de desenvolvimento em metodologia quantitativa. O positivismo comtiano, as "regras do método sociológico" e a noção de "fato social", introduzidas por Durkheim, dão uma base teórica e epistemológica mínima para o exercício de uma sociologia quantitativa. A "neutralidade axiológica" e o conceito de "tipos ideais" sugerido por Weber também são importantes para definir procedimentos desejáveis de tratamento do objeto científico. A grade curricular das ciências sociais costuma incluir as ideias destes autores sobre como fazer ciência, bastando, portanto, lembrá-las quando se pensa em metodologia. A fundamentação analítica dada pelos clássicos é a base para se construir estudos pautados na observação dos fatos e para se evitar ensaios ideológicos e políticos, contaminados por juízos de valores. Melhor ainda seria se as regras da prática sociológica, elencadas por estes autores, se vinculassem de forma explícita aos cursos de metodologia (e estatística) que compõem a formação do cientista social. A ponte entre "tipos ideais" e simulações estatísticas construídas a partir de modelos de regressão, por exemplo, ajudaria a entender e estender o que Weber quis dizer. Ao predizermos probabilidades para perfis prevalentes de uma amostra, estamos na verdade construindo tipos ideais weberianos, ou seja, construtos analíticos médios.

O segundo aspecto inclui uma boa formação em estatística. Isso começa na graduação e tende a consolidar-se no mestrado e/ou doutorado. Esse treinamento é essencial para ir-se além do espectro ensaístico que domina as ciências sociais brasileiras (Soares, 2005: 47).

Uma formação sólida envolve saber um pouco sobre processos de amostragem, estrutura de bancos de dados, e operacionalização, construção e diferença entre variáveis derivadas - proporções, taxas, índices, chances -, medidas de posição relativa, tendência central e variabilidade. Saber construir e interpretar medidas e modelos de associação entre variáveis também são habilidades essenciais para se produzir resultados com alguma validade externa e que potencialmente possam vir a sinalizar processos causais. É preciso que pelo menos a intuição por trás destas técnicas seja conhecida.

Embora os estudantes das ciências sociais precisem estar familiarizados com metodologia quantitativa para entender o que estão fazendo, para serem usuários das técnicas, não precisam entender a estatística a fundo. Precisam saber a semântica, mas não a etimologia do processo. É importante cultivar o interesse dos alunos pelo 
assunto para que superem a fobia numérica que muitos naturalmente trazem consigo, por terem escolhido a área de humanas ao invés de exatas.

O terceiro aspecto consiste em ter disciplina para aprender e se apropriar de outros métodos. Consiste em conseguir andar com as próprias pernas. Ser capaz de elaborar com clareza uma pergunta de pesquisa e escolher, com maturidade, o método mais apropriado para respondê-la. Os métodos de análise quantitativa não param de avançar e o seu aprendizado certamente não deve cessar ao término do processo de educação formal, mesmo porque mudanças curriculares são lentas e exigem que conhecimentos prévios estejam consolidados - sobretudo entre professores antes que a incorporação de novos conteúdos seja feita.

Um quarto aspecto relevante para o desenvolvimento da metodologia quantitativa nas ciências sociais refere-se ao aprendizado de métodos para a busca e sistematização de dados publicamente disponíveis (web scraping). Conhecer estas técnicas e saber se apropriar destes dados para o planejamento estratégico e tomada de decisões será essencial. A maioria dos cientistas sociais não é treinada para isso. Recebemos algum treinamento para analisar estas informações, mas as habilidades de programação, visualização e simulação de dados - com o $R$ e o Stata, por exemplo - são adquiridas de forma independente e não sistematizada. Esse tipo de treinamento ainda não entrou para o mainstream das ciências sociais, nem mesmo entre as universidades americanas de ponta.

Outras áreas promissoras em metodologia quantitativa nas quais ainda há pouca inserção nas ciências sociais brasileiras são:
i. causalidade;
ii. redes sociais; e
iii. sistemas adaptativos complexos baseados em agentes (agent-based models).

Debates causais na sociologia brasileira são raros, apesar de na sociologia americana e na economia terem grande importância (variáveis instrumentais, estratégias de pareamento, experimentos sociais, regressão descontínua, análises contra factuais através de simulações etc.). A análise formal de redes sociais também não tem recebido a devida atenção no Brasil. Um dos poucos casos é a sociologia da UFMG, que sob a coordenação do Prof. Silvio Salej, tem direcionado esforços para o treinamento e a consolidação deste campo no país. Por fim, uma promessa que vem rondando as ciências sociais há algum tempo são os sistemas adaptativos complexos e 
os modelos baseados em agentes, que prometem integrar as díades ação-estrutura, indivíduo-sociedade, agência-instituição. Aplicações destes modelos na sociologia brasileira, entretanto, são raras.

Certamente há ideias consolidadas sobre estes assuntos, ainda que algumas sejam dinâmicas e estejam inseridas em campos em contínua construção. Há vários manuais de métodos estatísticos para as ciências sociais (Agresti \& Finlay, 2012 é um bom exemplo). Há também muita coisa publicada sobre causalidade, redes sociais e sistemas adaptativos complexos baseados em agentes, mas a maioria está em inglês. A vanguarda da ciência é produzida - e reconhecida - neste idioma. No "mercado hierarquizado de bens linguísticos", o inglês pauta o debate global e é inegavelmente hegemônico, ainda que no caso das ciências humanas seja menos preeminente que nas ciências naturais devido à inserção do objeto social em contextos histórico-geográficos específicos (Ortiz, 2004). O aprendizado de metodologias pioneiras ainda depende, entretanto, do domínio desta língua. A habilidade de compreender textos em inglês tornou-se um pré-requisito não só para a capacitação plena, mas também para a inclusão intelectual.

Alguns nomes, em particular, são chave para uma introdução a estes temas e para se acompanhar o debate em andamento. Sobre causalidade, recomendo os livros de Morgan e Winship (2014), que são da sociologia, e os de Judea Pearl (2009, 2010), ganhador do prêmio Turing, o "Nobel da Computação", de 2011. Na área de análise de redes sociais, Wasserman e Faust (1994) é um dos primeiros manuais de introdução. Em português, sugiro dois livros: Christakis e Fowler (2010), para uma descrição acessível de diversas aplicações de redes sociais na vida cotidiana; e Lazega e Higgins (2014), para uma introdução sucinta sobre o tema. Por fim, na área de modelos baseados em agentes, um dos precursores é Nigel Gilbert (2007), que já escreveu dezenas de livros sobre o assunto, e participou até mesmo de um instrutivo "manifesto de ciência social computacional", publicado em português (Conte et alii, 2013). Essas seriam formidáveis aquisições para uma biblioteca, mas há também muita coisa gratuita na internet sobre estes mesmos assuntos.

Sob uma perspectiva global, a produção sociológica brasileira em metodologia quantitativa é pífia. Em média, sete de cada dez artigos publicados entre 1997 e 2012 nas principais revistas de ciências sociais brasileiras não utilizaram nenhum número (Neiva, 2015: 71). Nos Estados Unidos, essa proporção é de três em cada dez (Vijverberg 1997 apud Neiva 2015: 73).

Isso se dá por duas razões. Primeiro porque não produzimos metodologia quantitativa no sentido de elaboração, invenção e aprimoramento de técnicas de análise. 
Ainda estamos no estágio de aprendizado e adoção das técnicas inventadas pelos outros. Em economia eles chamam isso de "vantagem do atraso" (Gerschenkron, 1962). No Brasil não há periódicos voltados para o desenvolvimento de novas metodologias (como o Sociological Methodology e o Sociological Methods \& Research, por exemplo).

Em segundo lugar, não há incentivos institucionais para se divulgar resultados de pesquisas em meios de circulação de impacto global, que valorizam embasamentos quantitativos. De acordo com os critérios estabelecidos pela Coordenação de Aperfeiçoamento de Pessoal de Nível Superior (Capes), uma publicação em periódico nacional, escrito em português, pode ter o mesmo peso que uma publicação na Nature ou na Science. Para que a nossa produção científica se torne relevante, para que seja lida e citada, é preciso que ela dialogue com o que tem sido praticado no mundo e tenha qualidade para circular em veículos de maior impacto, que são em inglês. Esse ainda não é o caso das ciências sociais brasileiras.

A escassez de discussões sobre causalidade, Big Data, visualização de dados, análise de redes e experimentos sociais evidenciam a defasagem global das ciências sociais do Brasil, diferentemente da academia internacional, onde estes assuntos possuem canais específicos de divulgação e aparecem com frequência na mídia. Ainda estamos engatinhando nestas áreas e assim continuaremos enquanto não houver professores e pesquisadores formados nestes assuntos ou com grande interesse pelo tema para avançar estes campos. A UFMG tem sido precursora na oferta de treinamento quantitativo através do MQ e dos workshops anuais do Grupo Interdisciplinar de Pesquisa em Análise de Redes Sociais (Giars), mas ainda estamos muito atrás dos americanos e europeus nesse sentido. Para que estas e outras áreas da sociologia avancem é importante que as pessoas se treinem em metodologia quantitativa, e que o conhecimento adquirido seja aplicado.

Freitas e Ribeiro (2013), por exemplo, evidenciam a importância do treinamento quantitativo ao compararem os "avanços" das áreas de mobilidade social, criminologia e religião. Segundo os autores,

[...] a única que dispõe de um cânone a ser seguido é a de mobilidade. Não é possível fazer muita coisa nessa área [...] sem saber utilizar os modelos estatísticos mais sofisticados (Freitas \& Ribeiro, 2013: 102-103).

Na sociologia da religião, por outro lado, a dispersão dos temas e a falta de interesse dos pesquisadores em incorporar metodologias quantitativas em suas análises têm tolhido a superação de paradigmas nas últimas décadas. Em artigo mais re- 
cente, Rosas (2015) reforça esse ponto, ao mostrar que apesar das muitas teorias já produzidas, ainda falta consenso literário e testes empíricos sobre as mesmas no Brasil.

\section{A relação entre \\ a metodologia quantitativa e a metodologia qualitativa}

Em geral, essas duas metodologias são utilizadas concomitantemente?

Em relação à construção do objeto de pesquisa há uma preferência por uma ou outra das duas metodologias? Por quê?

Fale-nos a sua opinião sobre o debate em torno do critério da cientificidade atribuído a trabalhos que usam e que não usam dados quantitativos.

Nelson do Valle Silva: Em primeiro lugar, elas não só não são incompatíveis como são largamente complementares. O bom cientista social deve usar as duas coisas, porque elas se complementam. Veja bem, como eu falei, o método quantitativo, permite você avaliar teorias e fazer descobertas. Essas descobertas te colocam questões. E a primeira coisa que você faz com essas questões é: "vou olhar lá fora o que que é". O profissional digno desse nome deveria ter um treinamento bom nessas duas formas, porque elas são complementares.

Eu vou te dar um exemplo: uma vez eu trabalhei com um pessoal lá em Minas Gerais da Fundação João Pinheiro, que tinha o seguinte problema: cenas educacionais. Cada município tem seu sistema educacional de ensino básico. É absolutamente trivial a ideia de que quanto mais recursos o município tem, melhor funciona o seu sistema de ensino. Essa é uma hipótese absolutamente trivial e desinteressante. $\mathrm{O}$ que vai te interessar? Justamente aqueles casos em que o município é pobre, mas o sistema de ensino é bom. Você vai querer saber as razões do sucesso. E inversamente você vai querer saber o porquê aquele município com muito recurso tem um sistema péssimo. Você vai querer localizar quem é essa turma para poder descobrir. Esse é um exemplo de combinação dos dois métodos. Porque o modelo do tipo regressão te diz: "esses são os casos que eu não consigo explicar, que é o caso de municípios ricos que são têm péssimo ensino, e o caso de sucesso com poucos recursos". O que acontece? Depois que eu os localizei por meio do método quantitativo, eu vou lá tentar descobrir o porquê, por meio dos métodos qualitativos. A partir desse diagnóstico, eu irei às escolas, realizarei entrevistas com os diretores, com o secretário municipal, para tentar descobrir o que tem diferente que faz o sucesso ou o fracasso. E nós fizemos isso. 
A pesquisa que mencionei combina os dois métodos. Uma coisa não prescinde da outra e uma fertiliza a outra. Eu não poderia sair por aí pegando município à toa e tentando descobrir alguma coisa. Eu tenho um método que me permite localizar onde está o foco do interesse; que me possibilitará incorporar novas informações, informações relevantes para explicar o sucesso ou o fracasso. Por isso a formação tem que ser forte e complementar. Nada de maniqueísmo, isso é o bem e isso é o mal.

Uma das coisas curiosas desses tantos anos que eu dou aula de metodologia quantitativa é a recusa de aceitar que está entendendo. A pessoa muitas vezes se recusa a entender. As pessoas dizem: "eu não vou entender nunca isso" ou "não, não é possível que eu estou entendendo".

As motivações, para a seleção do objeto estão em outro lugar. Estão no seu envolvimento moral. Por exemplo, comigo é a questão da desigualdade. Então a motivação é ideológica, no sentido genuíno. Eu estou interessado nesse problema. Vejo como um problema social a ser resolvido e estou interessado nele, em entendê-lo. Então essa é a minha motivação. Agora como eu vou fazer depende do meu ponto específico de análise. Eu posso começar do zero, com ideia nenhuma, aí eu entro em termos qualitativos, eu vou tomando pé na coisa. Se eu já tenho algumas teorias antes, eu começo delas para ir caminhando, até chegar no momento: "eu não entendi nada, tenho que começar tudo de novo".

Não é o dado quantitativo que faz a coisa ser científica, tanto para o bem quanto para o mal. Você pode ter o uso de dados quantitativos com uma cientificidade de péssima qualidade, e boa parte do nosso mundo, fora da sociologia, é isso. Boa parte do conhecimento médico, nutricional, dessas áreas, é de péssima qualidade. Não existe evidência nenhuma. Por exemplo, não existe nenhuma evidência ligando o consumo de gordura com colesterol. A evidência é fajuta. No entanto, se produzem rios de tinta, programas de dieta e tudo mais. Não é exclusividade da nossa área o uso de métodos quantitativos. Usá-los mal não faz a ciência. o que faz a ciência é a análise cuidadosa das evidências que você tem. Essas evidências podem ser de natureza qualitativa, mas você precisa ter rigor no seu método.

Há uma ideia forte de que a análise qualitativa é papo de botequim. Você chama umas pessoas, conversa, e aquilo é uma maneira de obter os dados. Não é. Por exemplo, a seleção de respondente, de informante, é fundamental em um método como o grupo focal.

A ciência é obtida através dos cuidados na obtenção da informação. Esse é o ponto essencial, o que faz a ciência. O cuidado com a informação, como você obtém a 
informação. Ela tem que ocorrer de forma a permitir a generalização, que é o que faz a ciência. Agora é mais fácil quando você está usando um método quantitativo, porque tem toda uma teoria da generalização, que é o que estamos vendo aqui. O que é a probabilidade? Uma teoria de como você generaliza. Observa um caso e generaliza para o quê? Para o total, ok? Mas isso pode ser feito em termos de análise qualitativa se você tiver cuidado na obtenção da informação, na base de informação.

Jerônimo Muniz: Por tradição, convencionou-se que estas duas metodologias não se falam. Via de regra as pessoas ainda optam por uma ou outra já que, apesar de complementares, estas abordagens servem a propósitos distintos. Cada uma delas possui particularidades direcionadas para o que se pretende estudar, e sua apropriação dependerá do objeto de pesquisa. Métodos quantitativos lidam com bancos de dados, modelos estatísticos de associação, representatividade populacional e identificação de tendências médias no tempo e no espaço. Métodos qualitativos dão um aprofundamento sobre percepções, comportamentos, valores, hábitos, atitudes, opiniões e ideias que não têm espaço em grandes amostras. Permitem coletar detalhes do fenômeno de interesse através do relacionamento mais estreito e extenso entre entrevistados e entrevistador.

Apesar de suas especificidades, a combinação destas metodologias é plausível, desejável e possível. Existem softwares e técnicas de análise de conteúdo qualitativo extraordinárias. AtlasTI, NVivo, QDA Miner e Iramuteq fazem isso muito bem, permitindo identificar padrões e tendências em entrevistas e outros corpora textuais. $\mathrm{Na}$ UFMG, a Profa. Corinne Rodrigues criou um curso na pós-graduação em sociologia sobre a combinação e complementariedade destes métodos e foi um sucesso, resultando na publicação de um livro. Combinar metodologias quanti e quali é plenamente possível, mas requer colaboração científica, tempo, dinheiro e treinamento.

Um survey, por exemplo, fica muito enriquecido se precedido e sucedido por entrevistas abertas focalizadas, histórias de vida, grupos focais e outros instrumentos qualitativos (Soares, 2005: 49).

As duas técnicas dão respostas complementares para problemas comuns, não são substitutas. São como arroz e feijão, e não como manteiga ou margarina.

Trabalhos cooperativos sobre um mesmo objeto a partir de duas metodologias são muito bem-vindos para aumentar o conhecimento produzido sobre determinado fenômeno social ou político, mas essa triangulação tem custos com os quais geralmente não queremos arcar. A maioria dos prazos e recursos dos editais da Capes, 
do CNPq e das agências estaduais de fomento são incompatíveis com a amplitude da utilização conjunta destas duas abordagens. Ademais, aprender métodos quali e quanti requer muito tempo de treinamento e cria um perfil híbrido e desejável de pesquisador, mas que, na prática, pode acabar sendo um generalista sem aprofundamento em nenhuma das duas.

Eu sempre preferi a abordagem quanti por considerá-la mais fácil, mais rápida e mais generalizável que a abordagem quali. Fui treinado para preferir modelos estatísticos e para trabalhar com grandes bancos de dados. Venho fazendo isso desde a graduação. Entretanto, minha preferência não é compartilhada pela maioria dos estudantes de ciências sociais nem por meus colegas de profissão, como mostra a literatura (Aguiar, 2001; Neiva, 2015; Soares, 2005; Valle Silva, 1999). A maioria das pesquisas publicadas nos periódicos de ciências sociais do Brasil se caracteriza pela ausência de números. Há quem defenda que as ciências sociais brasileiras priorizam a teoria ao invés da empiria, o relativismo e a intuição ao invés do rigor e da sistematização, a erudição ao invés da prática (Cano, 2012; Reis, 1993). A aversão aos números parece não ter sido superada.

A escolha por abordagens não quantitativas (o que não implica na adoção rigorosa de abordagens qualitativas) deve-se a duas razões: a primeira delas é a carência de treinamento prévio adequado dos docentes; e a segunda é o "viés de seleção" do ingresso universitário (preferência por disciplinas como história, filosofia, português, ao invés de matemática e estatística).

O primeiro argumento torna-se evidente ao constatarmos que pesquisadores com doutorado na USP ou na França - onde se enfatiza formação teórica - possuem chances muito menores de utilizar métodos quantitativos do que aqueles formados nos Estados Unidos (Neiva, 2015: 79, quadro 6). A escolha pela utilização de métodos quanti ou quali decorre, portanto, das influências, preferências, oportunidades e do treinamento recebido ao longo da formação universitária. Tende-se a reproduzir o que se foi treinado para fazer. Escolhemos perguntas de pesquisa e metodologias com as quais temos maior afinidade. É natural que seja assim.

Comecemos pelo o que não é científico. Certos textos escritos por professores, pesquisadores, doutores e cientistas podem ter caráter meramente opinativo e refletir ideologias formadas a partir de experiências e posicionamentos políticos. Ensaios desta natureza não são ciência em si, ainda que o ethos de quem os escreva sugira o contrário. A atividade científica é pautada pela objetividade, e esta, por sua vez, pela análise informativa de processos e tendências, bem como pela observação e descrição de regularidades. O que torna um trabalho científico é a clareza da pergunta, a 
relevância, a sistematização teórico-metodológica e o rigor das observações feitas sobre o objeto de pesquisa.

A boa pesquisa científica também deve ser reproduzível, validada por pares e, idealmente, permitir generalizações. Todas estas características, exceto a última, são plenamente compatíveis com metodologias qualitativas. A única limitação da pesquisa qualitativa é, em função de sua operacionalização, a restrição de suas conclusões a um universo ou amostra específica. Por outro lado, ela tem a vantagem de apresentar maior validade interna e riqueza de detalhes, dificilmente captados pelos métodos quantitativos.

No debate sobre cientificidade, é preciso atentar-se para o fato de os dados quantitativos, captados em sua maioria a partir de pesquisas de opinião, não serem verdades observáveis, rígidas e imutáveis, mas sim o produto de processos cognitivos variáveis.

Estatísticas resultam de disputas políticas e são também socialmente construídas, estando permeadas por um componente subjetivo e instável. Poucos pesquisadores se questionam sobre a origem e a construção dos dados, ou sobre o impacto que condições estruturais e culturais podem ter sobre as respostas dadas a partir de categorias pré-definidas. Esse é o caso, por exemplo, das pesquisas que tentam mensurar o posicionamento político, a religião e a raça. Quando as pessoas se deparam com opções fixas de resposta, escolhem aquelas que, no momento da entrevista, possuem maior saliência. Entretanto, quando estas mesmas pessoas têm a oportunidade de falar e desenvolver ideias sobre tais temas, opiniões conflitantes e múltiplas emergem, fornecendo um retrato elaborado e mais detalhado da realidade social que se quer captar (Zaller \& Feldman, 1992).

Métodos quanti e quali, portanto, possuem virtudes e limitações, sendo suplementares e não excludentes. Estatísticas são uma poderosa ferramenta para se identificar padrões e para se persuadir audiências: "Um único número possui um valor mais genuíno e mais duradouro do que uma rica biblioteca repleta de hipóteses". Mas, por outro lado, esvaziam-se sem a compreensão dos mecanismos motivacionais da ação humana que as geraram. Ao fim e ao cabo, não é o método que define a pesquisa de qualidade, mas sim a habilidade do pesquisador em apropriar-se dele para responder, com propriedade e rigor, a perguntas relevantes. 
The quantitative methods, by Brazilian social scientists: interviews with Nelson do Valle Silva and Jerônimo Muniz

Abstract: In recent years, it has been observed growing interest in the study and use of quantitative techniques in Social Sciences. Similarly, there is a wider debate about its uses and the creation of new tools and approaches to the application of Quantitative Methodology in social and political studies. In order to reflect on these issues from theoretical and empirical experience, we interviewed two professors / researchers from different generations who are important references in the area, Prof. Dr. Nelson do Valle Silva, of Instituto de Estudos Sociais e Políticos da Universidade do Estado do Rio de Janeiro (IESP-UERJ) and Prof. Dr. Jerônimo Muniz, of the Universidade Federal de Minas Gerais (UFMG).

Key-words: quantitative methodology, biography, social sciences, statistics, teaching and research.

\section{Referências}

AGRESTI, A.; FINLAY, B. Métodos estatísticos para as ciências sociais. 4. ed. Série "Métodos de Pesquisa". Porto Alegre: Penso, 2012.

AGUIAR, Neuma. Qual a contribuição dos métodos quantitativos em ciências sociais para o conhecimento da sociedade brasileira? Comunicação apresentada no XXV Encontro Anual da Associação Nacional de Pós-Graduação e Pesquisa em Ciências Sociais (Anpocs), Caxambú, 2001. Disponível em: <http://portal.anpocs.org/portal/ index.php?option=com_docman\&task=doc_view\&gid=4570\&ltemid=356>. Acesso em: Set. 2015.

BAILEY, S.; LOVEMAN, M.; MUNIZ, J. O. Measures of "Race" and the analysis of racial inequality in Brazil. Social Science Research, v. 42, n. 1 p. 106-119, 2013.

BARBERÍA, L. G.; GODOY, S. R.; BARBOZA, D. P.; DUARTE, G. J.; ANJOS, J. R. M. $M$. Inovação no ensino de métodos quantitativos em ciência política: aplicação de modelo baseado em atividades. Revista de Discentes de Ciência Política da UFSCar, v. 2, n. 2, p. 152-179, 2014.

BOURDIEU, Pierre. A distinção: crítica social do julgamento. Porto Alegre: Zouk, 2007.

CHRISTAKIS, N.; FOWLER, J. O poder das conexões: a importância do networking e como ele molda nossas vidas. Rio de Janeiro: Elsevier, 2010.

CANO, Ignacio. Nas trincheiras do método: o ensino da metodologia das ciências sociais no Brasil. Sociologias, Ano 14, n. 31, p. 94-119, Porto Alegre, Set./Dez. 2012.

CONTE, R.; GILBERT, N.; BONELLI, G.; CIOFFI-REVILLA, C.; DEFFUANT, G.; KER- 
TÉSZ, J.; LORETO, V.; MOAT, S.; NADAL, JEAN-P.; SÁNCHEZ, A.; NOWAK, A.; FLACHE, A.; MIGUEL, M. S.; HELBING, D. Manifesto de ciência social computacional, Mediações, v. 18, n. 1, p. 55-65, 2013. Disponível em: <http://dx.doi.org/10.5433/ 2176-6665.2013v18n1p20>. Acesso em: 13 Out. 2015.

FIGUEIREDO FILHO, Dalson et alii. O que fazer e o que não fazer com a regressão: pressupostos e aplicações do modelo linear de mínimos quadrados ordinários (MQO). Revista Política Hoje, v. 20, n. 1, 2011.

FREITAS, R. S.; RIBEIRO, L. Avanços e perspectivas da sociologia no Brasil: uma abordagem comparativa. Revista Brasileira de Sociologia, v. 1, n. 2, p. 69-113, 2013.

GERSCHENKRON, A. Economic backwardness in historical perspective. Cambridge (MA): Harvard University Press, 1962.

GILBERT, Nigel. Agent-based models. London: Sage Publications Inc, 2007.

GUNTHER, Hartmunt. Pesquisa qualitativa versus pesquisa quantitativa: esta é a questão? Psicologia: Teoria e Pesquisa, v. 22, n. 2, p. 201-210, Maio-Ago. 2006.

INSTITUTO DE PESQUISAS ECONÔMICAS APLICADAS (IPEA). Perspectivas profissionais: nível técnico e superior. Radar: Tecnologia, Produção e Comércio Exterior, n. 27, Ago. 2013. Disponível em: <http://www.ipea.gov.br/portal/index.php?option=com_content\&view=article\&id=18830\&Itemid=8>. Acesso em: 24 Set. 2015.

KHAN, Salman. Um mundo, uma escola: a educação reinventada. Rio de Janeiro: Intrínseca 2013.

LAZEGA, Emmanuel; HIGGINS, Silvio. Redes sociais e estruturas relacionais. Belo Horizonte: Fino Traço, 2014.

LOVEMAN, Mara; MUNIZ, Jeronimo O. How Puerto Rico became white: boundary dynamics and intercensus racial classification. American Sociological Review, v. 72, p. 915-939, 2007.

LOVEMAN, Mara; MUNIZ, Jeronimo O.; BAILEY, S. Brazil in black and white? Race categories, the census, and the study of inequality. Ethnic and Racial Studies, v. 35, n. 8, p. 1466-1483, 2012.

LOVEMAN, Mara; MUNIZ, Jeronimo O.; COLLARES, Ana Cristina. Brazil - Sociology. Handbook of Latin American Studies, v. 63. Washington: United States Library of Congress, 2008. 
MILLS, Wright. A imaginação sociológica. Rio de Janeiro: Zahar Editores, 1975.

MORGAN, S.; WINSHIP, C. Counterfactuals and causal inference: methods and principles for social research. 2. ed. Cambridge: Cambridge University Press, 2014.

MUNIZ, J. O. Demographic dynamics of poverty and inequality: the case of Brazil. Revista Brasileira de Estudos de População, v. 29, n. 2 p. 323-348, 2012 a.

Preto no branco? Mensuração, relevância e concordância classificatória no país da incerteza racial. Dados - Revista de Ciências Sociais, v. 55, n. 1 p. 165-195, 2012b.

Sobre o uso da variável raça-cor em estudos quantitativos. Ver. Sociol. Polít., v. 18, n. 36 p. 277-291, 2010.

- Spatial dependence and heterogeneity in ten years of fertility decline in Brazil. Population Review, v. 48, n. 2, p. 32-65, 2009.

— - As descontinuidades demográficas exercem efeitos sobre o mercado de trabalho metropolitano dos jovens? Revista Brasileira de Estudos de População, v. 19, n. 2 p. 65-98, 2002.

NEIVA, P. Revisitando o calcanhar de Aquiles metodológico das ciências sociais no Brasil. Sociologia, Problemas e Práticas, v. 79, p. 65-83, 2015.

ORTIZ, Renato. As ciências sociais e o inglês. Rev. bras. Ciências Sociais, v. 19, n. 54 p. 5-22, 2004.

PEARL, J. An introduction to causal inference. The International Journal of Biostatistics, v. 6: iss. 2, article 7, 2010.

- Causality: models, reasoning and inference. 2. ed. Cambridge (UK): Cambridge University Press, 2009.

RAMOS, M. Métodos quantitativos e pesquisa em ciências sociais: lógica e utilidade do uso da quantificação nas explicações dos fenômenos sociais. Mediações, v. 8, n. 1, p.55-65, Londrina, 2013.

REIS, Fábio W. Avaliação das ciências sociais. Belo Horizonte: UFMG, 1993. Disponível em: <http://www.schwartzman.org.br/simon/scipol/pdf/csociais.pdf>. Acesso em: Set. 2015.

ROSAS, N. Sociologia da religião: comentário a um balanço sobre a produção do conhecimento. Revista Mediações, Abr./ Maio 2018 (no prelo). 
- Sociologia da religião: um balanço a respeito da produção do conhecimento. Belo Horizonte, 2015 (mimeo).

ROSAS, N.; MUNIZ, J. O. Does the habit make the nun? Religious frequency and self-perception of religion in Brazil. Mediações, v. 19, n. 1 p. 187-213, 2014.

SILVEIRA, L. S.; MUNIZ, J. O. Variações intra e intermetropolitanas da desigualdade de renda racial. Cad. Metrop., v. 16, n. 31, p. 265-289, 2014.

SOARES, G. O calcanhar metodológico da ciência política no Brasil. Sociologia, Problemas e Práticas, n. 48, p. 27-52, 2005.

VALLE SILVA, N. Relatório de consultoria sobre melhoria do treinamento em ciência social quantitativa e aplicada no brasil. Rio de Janeiro, 1999 (mimeo).

VEBLEN, Thorstein. The theory of the leisure class: an economic study of institutions. New York; London: Macmillan, 1899.

VIANNA, L. W.; CARVALHO, M. A. R. DE; MELO,M. P. C.; BURGOS, M. B. Doutores e teses em ciências sociais. Dados, v. 41, n. 3, p. 453-515, 1998.

WASSERMAN, Stanley; FAUST, Katherine. Social network analysis. New York: Cambridge University Press, 1994.

ZALLER, John; FELDMAN, Stanley. A simple theory of survey response: answering questions versus revealing preferences. American Journal of Political Science, v. 36, n. 3 p. 579-616, 1992. 
